\title{
A GEMOLOGICAL LOOK AT KYOCERA'S NEW SYNTHETIC STAR RUBY
}

\author{
By John I. Koivula and Robert C. Kammerling
}

\begin{abstract}
Kyocera Corporation of Kyoto, Japan, is currently marketing under the trade name "Inamori" a macroscopically natural-appearing semitransparent asteriated synthetic ruby. With the exception of obvious internal characteristics and a relatively strong fluorescence to ultraviolet radiation, all of the gemological properties shown by this material are essentially the same as those encountered in natural star rubies. For the maiority of gemologists without access to research-grade testing equipment, the internal characteristics of Kyocera's synthetic star ruby are the only universally reliable means of identifying this new product.
\end{abstract}

Since late 1986, Kyocera America Corporation's Inamori Gemstone Division has been marketing a number of new, high-quality synthetic materials under the trade name "Inamori." Until the introduction of this Inamori line, Kyocera was selling their synthetics only in a flawless grade under the trade name "Crescent Vert." According to Kyocera America's April 1, 1987, press release, "The new Inamori line will offer three grades [in some cases, two in others| with characteristic inclusions in response to customer demand for gemstones which more closely match the mined stone."

The two most interesting among these new offerings are the synthetic cat's-eye alexandrite (described in Kane, 1987, and Koivula et al., 1988), and the synthetic star ruby. Both are stated to be manufactured, "from a proprietary method," by their parent company, Kyocera Corporation, which is headquartered in Kyoto, Japan.

To provide the gemological community with information on their new product, Kyocera loaned the Gemological Institute of America five sample cabochons of this new synthetic star ruby for study. The results of this detailed examination are reported below.

\section{DESCRIPTION}

The largest round and oval stones supplied by Kyocera (figure 1) are well-polished cabochons that weigh 1.99 and $1.60 \mathrm{ct}$, respectively. The remaining three samples weigh $0.92 \mathrm{ct}$ (oval), $1.46 \mathrm{ct}$

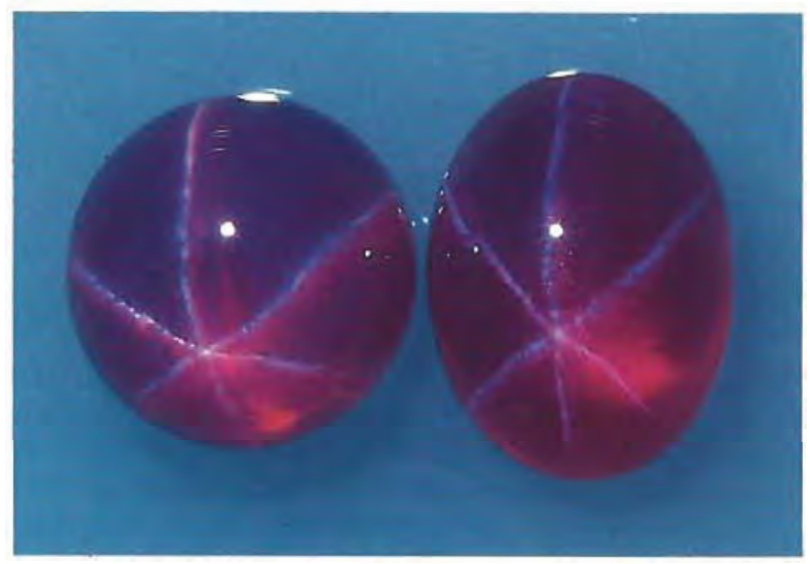

Figure 1. Shown here are the largest round (1.99 ct) and oval $(1.60 \mathrm{ct})$ cabochons of Kyocera synthetic star ruby studied for this report. Note the near-transparency "and slightly imperfect stars.

(oval), and $1.95 \mathrm{ct}$ (round). All five of the cabochons are semitransparent with flat, semi-polished backs.

When viewed with an overhead incandescent light source, all of the stones display relatively sharp and intense, white, six-rayed stars. Unlike the perfect stars of the Union Carbide ("Linde") synthetic star rubies, the Kyocera stars show very convincing imperfections, such as slightly wavy or broken rays, which make them appear much more natural (again, see figure 1). Some of the cabochons also exhibit less than perfect surfaces with slight pitting evident. The body color of these synthetic

\footnotetext{
ABOUT THE AUTHORS

John 1. Koivula is chief gemologist and Robert C. Kammerling is general manager of technical development at the Gemological Institute of America.

Acknowledgments: The authors are grateful to Mr. Ken Takada, former director of the jewelry division of Kyocera America, Inc. for supplying the Inamori star rubies. Thanks also $10 \mathrm{Mr}$. Dino DeGhionno at GIA for his assistance in obtaining the specimens. Mr. Chuck Fryer pertormed the X-ray diffraction, Ms. Carot M. Stockton provided the chemical analysis, and Dr. Emmanuel Fritsch supplied the intrared spectroscopy. All photographs and photomicrographs are by John t. Koivula.

(1) 1989 Gemologicai Institule of America
} 
TABLE 1. The gemological properties of the Kyocera synthetic star ruby.

\begin{tabular}{|c|c|}
\hline \multicolumn{2}{|c|}{$\begin{array}{l}\text { Properties that overlap those } \\
\text { of natural star rubies }\end{array}$} \\
\hline Color & Slightly purplish red \\
\hline Visual appearance & $\begin{array}{l}\text { Very convincing body color with slight } \\
\text { imperfections to the asterism }\end{array}$ \\
\hline Refractive index $x^{a}$ & Spot readings of $1.76-1.77$ \\
\hline Polariscope reaction & Uniaxial optic figures \\
\hline Pleochroism & Strong orangy red and purplish red \\
\hline Color filter reaction & Bright red \\
\hline Specific gravity & $\begin{array}{l}4.00 \pm 0.02 \text { using Clerici's solution } \\
\text { with indicator }\end{array}$ \\
\hline Absorption spectrum & $\begin{array}{l}\text { Identical to the spectrum shown by } \\
\text { natural ruby }\end{array}$ \\
\hline
\end{tabular}

Key identifying properties

Ultraviolet fluorescence ${ }^{b}$

Long-wave

Short-wave

Very strong red

Strong to very strong red with a moderate to strong superficial chalky blue-white overtone

Inclusions ${ }^{c}$

Extremely fine white-appearing exsolution rutile. Numerous bluish white smoke-like swirls. Both round and distorted gas bubbles.

aln their promotional brochure, Kyocera reports a more accurate refractive index reading of 1.762-1.770 with a corresponding birefringence of 0.008 . This had to be taken on a flat well-polished surface which was not available to the authors of this report.

bTesting done in total darkness (darkroom conditions). Useful if known fluorescence comparison stones are used.

'Observed using fiber-optic illumination and/or shadowing.

rubies is a very natural looking slightly purplish red that compliments their near-transparency.

From the back, because of their flat, semipolished bases, these synthetic star rubies "look

Figure 2. The exsolution needles that form the star in Kyocera synthetic ruby are extremely fine. Incident fiber-optic illumination; magnified $25 \times$.

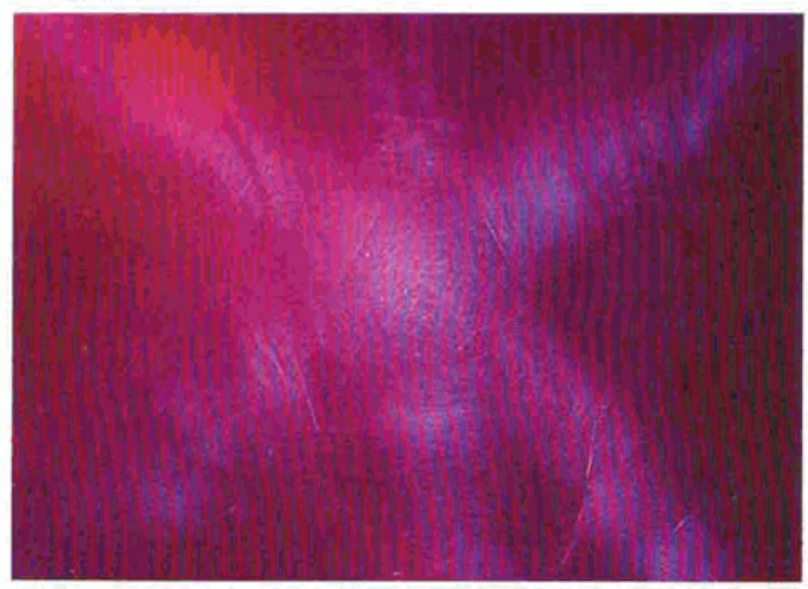

synthetic." This is a cutting style gemologists have come to associate with synthetic star corundum similar to that produced by the Linde division of Union Carbide. Should these backs be roughed and rounded, however, without magnification they would look very natural.

\section{GEMOLOGICAL PROPERTIES}

The gemological properties determined on these five samples agreed for the most part with those reported by Kyocera in their promotional literature. As indicated in table 1, with the exception of fluorescence and internal characteristics, the properties of the Inamori synthetic star ruby overlap those of their natural counterparts. The distinctive features are described below.

Reaction to Ultraviolet Radiation. When exposed to long-wave ultraviolet radiation, the Kyocera synthetic star rubies all fluoresced a very strong red. The short-wave reaction appeared to be slightly weaker with a variable (moderate to strong) superficial chalky blue-white overtone that was most obvious when the lamp was held very close to the stone and the room was in total darkness (darkroom conditions). No phosphorescence was observed in any of the stones. If rubies of known origin were used as indicators in fluorescence testing, perhaps this reaction would prove useful in providing evidence of synthesis.

Microscopy. When we examined the samples with a gemological microscope, the first thing we noticed was the fineness of the exsolution "rutile" needles (figure 2) when compared to the rutile

Figure 3. The star-causing exsolution rutile needles in this Burmese ruby are much coarser than those observed in the Inamori synthetic. Incident fiber-optic illumination; magnified $30 \times$.

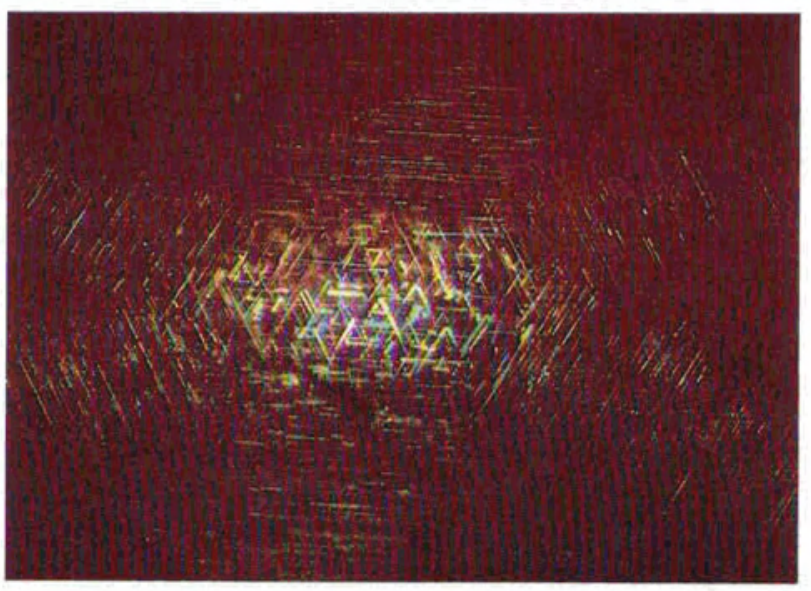




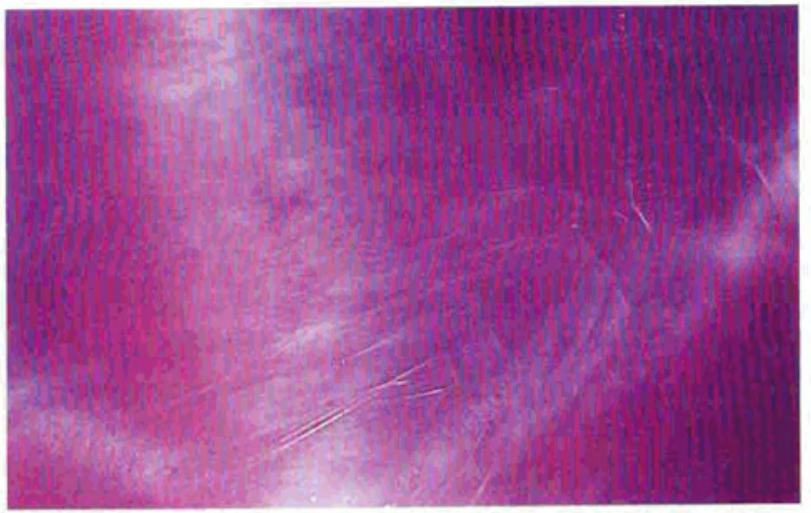

Figure 4. Present in all five specimens examined, these white smoke-like patterns, together with the fineness of the asterism-causing needles, provide proof of synthesis. Darkfield and oblique fiber-optic illumination; magnified $50 \times$.

needles typically responsible for asterism in natural star rubies (figure 3).

When fiber-optic illumination was used, numerous smoke-like, bluish white, swirling wispy veils were seen running haphazardly between the star's rays (figure 4) throughout all five synthetic stones. These swirls are composed of white-appearing matter that is far too fine to be resolved with a standard gemological microscope.

Similar-appearing swirls have been observed in very poor quality Czochralski-pulled synthetic ruby and suggest that Kyocera's star rubies are crystallized from a high-temperature melt process, such as Czochralski pulling, rather than grown as euhedral crystals in a flux or hydrothermal environment. The absence of curved striae suggests that the flame-fusion process was not used. The 1.99-ct stone shows a crude hexagonal pattern through its apex that appears to be surrounded by swirls (figure 5) and may be the trace remnant of a seed.

Particularly distinctive of this synthetic is the presence of gas bubbles, both round and distorted. In shadowed transmitted light (figure 6) the swirls are observed as dark-edged wavy bands, while the gas bubbles, although small, stand out in relatively high relief.

We also noticed that one stone had a tiny chip with a pronounced conchoidal fracture. While this type of fracture can also be seen in natural rubies and sapphires, it is rare in natural stones because, when put under excessive stress, natural gems are more likely to separate along weak parting planes, leaving a flat break similar to a cleavage surface.

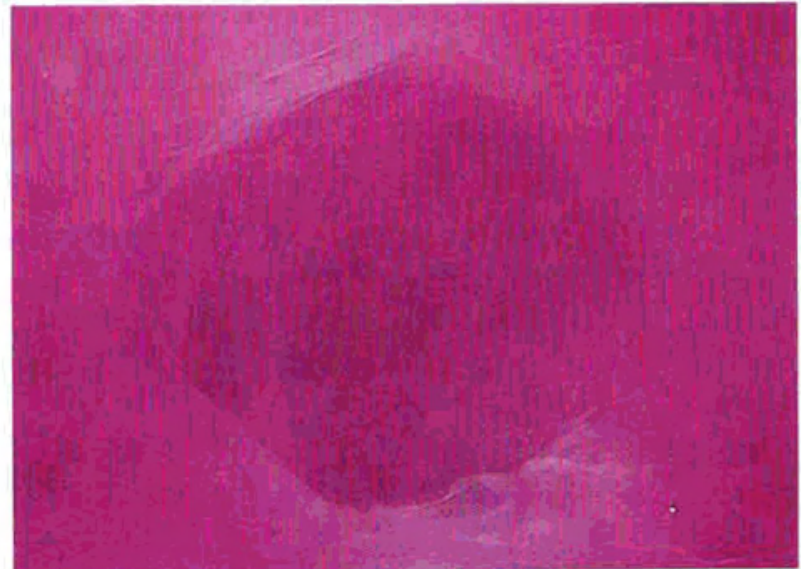

Figure 5. A crude hexagonal pattern seen through the apex of the 1.99-ct stone may be the trace remnant of a seed. Transmitted and oblique fiber-optic illumination; magnified $35 \times$.

In general, the internal features in Kyocera's product in no way resemble the suite of characteristic inclusions recognized thus far in natural star corundums (Gübelin and Koivula, 1986). On the basis of their inclusions, these new synthetic star rubies are easy to distinguish from the natural.

\section{INFRARED SPECTROSCOPY}

Using a Nicolet 60SX Fourier-transform infrared spectrometer, Dr. Emmanuel Fritsch tested the mid-range infrared absorption characteristics of one of the synthetic star rubies (in a direction normal to the cabochon's base) to check for the possible presence of water within the structure. No structural water could be detected.

This lack of water adds support to the premise

Figure 6. In addition to the wavy patterns, small gas bubbles, both round and distorted, are sometimes observed. Shadowed transmitted light; magnified $50 \times$.

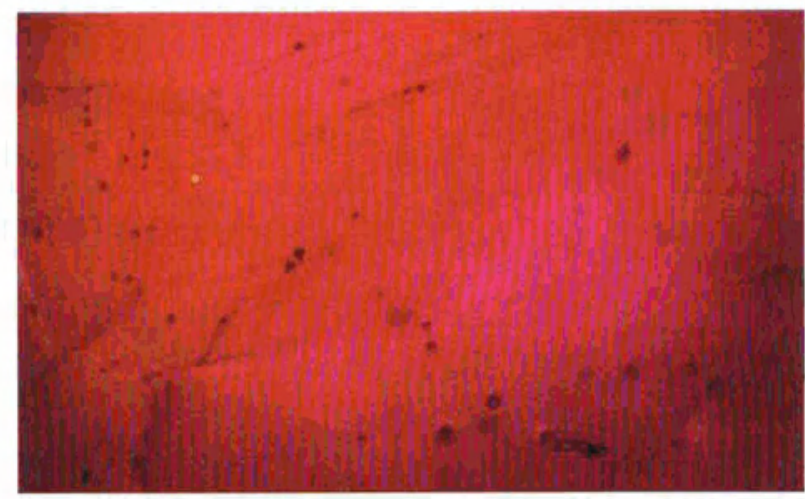


that Kyocera's new synthetic star rubies are crystallized from a high-temperature melt using a process such as Czochralski pulling or Verneuil flame fusion.

\section{QUALITATIVE CHEMICAL ANALYSIS}

Ms. Carol Stockton examined one of the synthetic star rubies in GIA's Tracor Northem energy dispersive $\mathrm{X}$-ray fluorescence unit to determine qualitatively what elements were present within the specimen's structure.

The cabochon was mounted, semi-polished base down, in a transparent Mylar-floored cup. The sample chamber was evacuated and the stone subjected to a tube voltage of $20 \mathrm{kV}$ and a tube current of $0.10 \mathrm{~mA}$ for a 100 -second measurement.

In addition to aluminum, traces of chromium (the color-producing chromophore) and titanium (the asteriating agent) were present, as expected. Very minor traces of calcium and iron were also detected and may be the result of a slight contamination in the feed chemicals. The fact that no gallium was found is a very strong indication of synthesis, since, in nature, aluminum-containing compounds such as corundum always contain traces of gallium. Oxygen, another major component in this chemical system, is not detectable with the Tracor unit.

\section{X-RAY DIFFRACTION}

To confirm the corundum identification, we asked Mr. Chuck Fryer to do an X-ray powder diffraction analysis on the sample material. A spindle of powder from one of the cabochons was prepared and mounted in a Debye-Scherrer powder camera. The resulting pattern matched the JCPDS standard for corundum, thus proving the identification.

\section{CONCLUSION}

This study of the new Inamori synthetic star ruby was based on an examination of only five polished cabochons. According to Kyocera's April 1, 1987, press release, the company is marketing only two grades of synthetic star ruby. These grades are designated "A" ("almost pure stones") and " $\mathrm{B}$ " ("very slightly flawed stones"). Both grades were represented in the samples studied by the authors.

Although very close, the key gemological properties, as listed by Kyocera in their brochure, are not in exact agreement with those obtained by the authors during testing. The properties listed in the brochure may reflect average values for a great number of stones.

With the exception of ultraviolet fluorescence and internal characteristics, all of the other gemological properties of these synthetic star rubies, such as specific gravity and refractive index, overlap with those shown by natural star rubies. Qualitative chemical analyses will also provide a positive identification, but the sophisticated equipment necessary is not readily available to the jeweler-gemologist. While ultraviolet fluorescence may provide a useful clue that the material is probably synthetic, the authors feel that this criterion alone is not sufficient to give a positive identification. Microscopy is the key to identifying Kyocera's new synthetic star rubies.

\section{REFERENCES}

Gübelin E.J., Koivula J.I. (1986) Photoatlas of Inclusions in Gemstones. ABC Edition, Zurich, Switzerland.

Kane R.E. (I987) Inamori synthetic cat's-eye alexandrite. Gems e. Gemology, Vol. 23, No. 3, pp. 158-162.

Koivula J.I., Fritsch E., Fryer C. (1988) The gemmological characteristics of Inamori synthetic cat's-eye alexandrite chrysoberyl. Journal of Gemmology, Vol. 2l, No. 4, pp. $232-236$. 